\title{
Discurso del Nobel 2014 Patrick Modiano ${ }^{1}$
}

\author{
Traducción de Yves Moñino ${ }^{2}$ \\ Centro Nacional de Investigaciones Científicas de Francia
}

Quisiera decirles sencillamente cuan feliz estoy entre ustedes y cuánto estoy emocionado del honor que me han hecho al concederme este premio Nobel de Literatura.

Es la primera vez que debo pronunciar un discurso ante tan numerosa asamblea y siento cierta aprensión de ello. Uno tendría la tentación de creer que para un escritor es natural y fácil entregarse a este ejercicio. Pero un escritor $-\mathrm{o}$ al menos un novelista- tiene con frecuencia relaciones difíciles con la palabra. Y si uno recuerda esta distinción escolar entre escrito y oral, un novelista está más dotado para lo escrito que para lo oral. Suele callarse y si quiere compenetrarse de una atmósfera, tiene que confundirse con la multitud. Escucha las conversaciones sin que nadie se dé cuenta, y si interviene en estas, es siempre para hacer unas preguntas discretas con el fin de entender mejor a las mujeres y los hombres que lo rodean. Tiene una palabra vacilante, por su costumbre de tachar sus escritos. Claro que después de múltiples tachones, su estilo puede parecer nítido. Pero cuando toma la palabra, ya no tiene el recurso de corregir sus vacilaciones.

Y luego pertenezco a una generación en que no dejaban hablar a los niños, salvo en ciertas ocasiones bien escasas y si estos pedían permiso. Pero no los escuchaban y a menudo les cortaban la palabra. Esto

\footnotetext{
${ }^{1}$ Discurso del novelista francés Patrick Modiano, leído al recibir el Premio Nobel de literatura el 7 de diciembre de 2014. «Patrick Modiano - Conférence Nobel». Nobelprize.org. Nobel Media AB 2014. Web. 8 Dec 2014. <http://www.nobelprize.org/nobel_prizes/literature/laureates/2014/ modiano-lecture_fr.html>

${ }^{2}$ Traducción de Yves Moñino. El profesor Moñino es Doctor de Estado de la Universidad de Paris 5-Sorbona. Etnolingüista en el Centro Nacional de Investigaciones Científicas de Francia-CNRS-, recientemente jubilado. Es especialista en lenguas y civilizaciones de Centroáfrica, Camerún y de los dos Congos. Trabaja desde 1993 en Colombia con los afrodescendientes del Palenque de San Basilio para contribuir al conocimiento de su lengua criolla y de las instituciones de esta comunidad, y con el fin de evaluar la importancia de su herencia congolesa, particularmente kikongo. Ha publicado cinco libros y más de cincuenta artículos en revistas científicas, de los cuales unos diez son sobre Colombia.
} 
es lo que explica la dificultad de elocución de algunos de nosotros, a veces vacilante, a veces demasiado rápida, como si temiéramos a cada rato que nos interrumpieran. De ahí, quizás, ese deseo de escribir que me agarró, como a muchos, al salir de la infancia. Uno espera que los adultos lo leerán. Así estarán obligados a escucharlo sin interrumpirlo y sabrán de una vez los resquemores de uno.

El anuncio de este premio me ha parecido irreal y estaba impaciente de saber por qué me habían escogido. Ese día, creo que nunca sentí de manera tan fuerte cuánto un novelista es ciego frente a sus propios libros y cuánto los lectores saben más que él de lo que ha escrito. Un novelista nunca puede ser su lector, salvo para corregir en su manuscrito faltas de sintaxis, repeticiones o suprimir un párrafo que sobra. No tiene sino una representación confusa y parcial de sus libros, como un pintor ocupado en hacer un fresco en el techo y que, tumbado en un andamio, trabaja en los detalles, desde muy cerca, sin visión del conjunto.

Curiosa actividad solitaria la de escribir. Uno pasa por momentos de desaliento cuando redacta las primeras páginas de una novela. Tiene, cada día, la impresión de confundir el rumbo. Y entonces es grande la tentación de volverse atrás y de adentrarse en otro camino. No hay que sucumbir a esta tentación sino seguir el mismo camino. Es un poco como estar conduciendo un carro, por la noche, en invierno y manejar sobre el hielo, sin ninguna visibilidad. Uno no tiene escogencia, no puede hacer marcha atrás, debe seguir avanzando diciéndose que la carretera acabará siendo más estable y que la niebla se desvanecerá.

En el momento de terminar un libro, a uno le parece que este empieza a arrancarse de él y que ya respira el aire de la libertad, como los niños, en el aula, en vísperas de las vacaciones. Están distraídos y ruidosos y ya no escuchan a su profesor. Hasta diría que en el momento en que uno escribe los últimos párrafos, el libro le manifiesta cierta hostilidad en su afán de liberarse de uno. Y lo deja apenas ha trazado la última palabra. Se acabó, ya no lo necesita, ya se olvidó de uno. Son los lectores que ahora lo revelarán a uno mismo. Uno siente en ese momento un gran vacío y el sentimiento de haber sido abandonado. Y también una especie de insatisfacción a causa de este lazo entre el libro y uno, que fue cortado demasiado rápido. Esta insatisfacción y 
este sentimiento de algo incumplido lo empujan a uno a escribir el libro siguiente para restablecer el equilibrio, sin que lo logre jamás. A medida que los años pasan, los libros se suceden y los lectores hablarán de una «obra». Pero tendrá el sentimiento que no se trataba sino de una larga huida hacia adelante.

Sí, el lector sabe más sobre un libro que su autor mismo. Ocurre, entre una novela y su lector, un fenómeno análogo al del revelado de las fotos, tal como lo practicaban antes de la era numérica. En el momento de su positivado en el cuarto negro, la foto se volvía poco a poco visible. A medida que uno avanza en la lectura de una novela, se desarrolla el mismo proceso químico. Pero para que exista semejante acuerdo entre el autor y su lector, es necesario que el novelista no « fuerce » nunca a su lector -en el sentido en que se dice de un cantante que fuerza su voz- sino que lo conlleve imperceptiblemente y le deje un margen suficiente para que el libro lo impregne poco a poco, y esto por un arte que se asemeja a la acupuntura, en la que es suficiente picar la aguja en un sitio muy preciso y el flujo se propaga en el sistema nervioso.

Esta relación íntima y complementaria entre el novelista y su lector, creo que encontramos su equivalente en el campo musical. Siempre pensé que la escritura estaba cercana a la música pero mucho menos pura que esta y siempre envidié a los músicos que me parecían practicar un arte superior a la novela $-\mathrm{y}$ a los poetas, que están más cercanos a los músicos que los novelistas. Empecé a escribir poemas en mi niñez y es quizás gracias a eso que entendí mejor la reflexión que leí en alguna parte: «Es con malos poetas que se hacen prosistas.» Y luego, en lo que concierne a la música, muchas veces se trata para un novelista de acarrear a todas las personas, los paisajes, las calles que pudo observar en una partitura en donde se encuentran los mismos fragmentos melódicos de un libro a otro, pero una partitura que le parecerá imperfecta. Habrá en el novelista la añoranza de no haber sido un puro músico y de no haber compuesto Los Nocturnos de Chopin.

La falta de lucidez y de distancia crítica de un novelista frente al conjunto de sus propios libros también tiene que ver con un fenómeno que observé en mi caso y en el de muchos otros: cada libro nuevo, en el momento de escribirlo, borra el precedente hasta el punto que tengo 
la impresión de haberlo olvidado. Creía haberlos escrito uno tras otro de manera discontinua, a fuerza de olvidos sucesivos, pero a menudo las mismas caras, los mismos nombres, los mismos lugares, las mismas frases vuelven del uno al otro, como los motivos de un tapiz que uno habría tejido en un entresueño. Un entresueño o un sueño despierto. Un novelista es a menudo un sonámbulo, tanto está penetrado por lo que debe escribir, y podemos temer que lo atropellen cuando atraviesa una calle. Pero olvidamos esta extrema precisión de los sonámbulos que caminan sobre los techos sin caer jamás.

En la declaración que siguió el anuncio de este premio Nobel, me fijé en la frase siguiente, que era una alusión a la última guerra mundial: «Desveló el mundo de la Ocupación.» Yo soy, como todas y todos los nacidos en 1945, un niño de la guerra, y más precisamente, pues nací en París, un niño que debió su nacimiento al París de la Ocupación. Las personas que vivieron en ese París muy pronto quisieron olvidarlo, o recordar solo detalles cotidianos, de los que daban la ilusión que después de todo la vida de cada día no había sido tan diferente de la que llevaban en tiempo normal. Una pesadilla y también un borroso remordimiento de haber sido de alguna manera supervivientes. Y cuando sus hijos los interrogaban más tarde sobre ese período y sobre ese París, sus respuestas eran evasivas. O guardaban silencio como si quisiesen borrar de su memoria esos años oscuros y ocultarnos algo. Pero ante los silencios de nuestros padres, adivinamos todo, con si lo hubiésemos vivido.

Ciudad extraña ese París de la Ocupación. En apariencia, la vida seguía, «como antes»: los teatros, los cines, las salas de music hall, los restaurantes estaban abiertos. Se oían canciones en la radio. Hasta había en los teatros y los cines mucha más gente que antes de la guerra, como si esos lugares fueran refugios donde la gente se juntaba y se apretaba unos contra otros para tranquilizarse. Pero detalles insólitos indicaban que París ya no era el mismo que antaño. A causa de la ausencia de los carros, era una ciudad silenciosa -un silencio en que se oía el susurro de los árboles, el choque de los cascos de los caballos, el ruido de los pasos de la multitud en los bulevares y el guirigay de las voces. En el silencio de las calles y del blackout que caía en invierno hacia las cinco de la tarde y durante el cual la menor luz en las ventanas estaba prohibida, 
esta ciudad parecía ausente de sí misma - la ciudad «sin mirada», como decían los ocupantes nazis. Los adultos y los niños podían desaparecer de un instante al otro, sin dejar ninguna huella, y hasta entre amigos, se hablaba a medias palabras y las conversaciones nunca eran francas, porque uno sentía una amenaza rondando en el aire.

En ese París de pesadilla, donde uno corría peligro de ser víctima de una denuncia y de une redada, a la salida de una estación de metro, se producían encuentros azarosos entre personas que nunca se hubieran cruzado en tiempos de paz, nacían amores precarios a la sombra del toque de queda sin que uno estuviera seguro de volver a encontrarse los días siguientes. Y es después de esos encuentros, a menudo sin futuro, y a veces de esos malos encuentros, que nacieron niños más tarde. Es por eso que el París de la Ocupación siempre fue para mí como una noche original. Sin él nunca habría nacido. Ese París no ha dejado de habitarme y su luz velada a veces baña mis libros.

Esto es también la prueba de que un escritor está marcado de manera indeleble por su fecha de nacimiento y por su tiempo, así no haya participado de manera directa en la acción política, así dé la impresión de ser un solitario, retirado en lo que se llama «su torre de marfil». Y si escribe poemas, estos son hechos a imagen y semejanza del tiempo en que vive y no habrían podido ser escritos en otra época.

Así el poema de Yeats, este gran escritor irlandés, cuya lectura siempre me estremeció profundamente: Los cisnes salvajes en Coole. En un parque, Yeats observa cisnes que se deslizan sobre el agua:

El decimonoveno otoño bajó sobre mí

Desde que los conté por primera vez;

Los vi, antes de haber podido acabar el conteo

Se elevaban de repente

Y se divertían arremolinándose en grandes círculos quebrados

Sobre sus alas tumultuosas

Pero ahora se deslizan sobre las aguas tranquilas

Majestuosos y llenos de belleza.

¿Entre qué juncos harán su nido,

En la orilla de qué lago, de qué estanque 
Encantarán otros ojos cuando despierte

Y averigüe, un día, que se echaron a volar?

Los cisnes aparecen a menudo en la poesía del siglo XIX -en Baudelaire o en Mallarmé. Pero este poema de Yeats no hubiera podido ser escrito en el siglo XIX. Por su ritmo particular y su melancolía, pertenece al siglo XX y hasta al año en que fue escrito.

Ocurre también que un escritor del siglo XXI se sienta, a ratos, preso de su tiempo y que la lectura de los grandes novelistas del siglo XIX -Balzac, Dickens, Tolstoi, Dostoievski- le inspire alguna nostalgia. En esa época, el tiempo corría de una manera más lenta que hoy en día y esa lentitud se armonizaba con el trabajo del novelista porque podía concentrar mejor su energía y su atención. Desde entonces, el tiempo se ha acelerado y avanza por sacudidas, lo que explica la diferencia entre los grandes macizos novelescos del pasado, con arquitecturas de catedrales, y las obras discontinuas y parceladas de hoy. Dentro de esta perspectiva, pertenezco a una generación intermediaria y estaría curioso de saber cómo las generaciones siguientes que nacieron con la internet, el celular, los mails y los tweets expresarán por medio de la literatura este mundo al cual cada uno está «conectado» en permanencia y donde las «redes sociales» merman la parte de intimidad y de secreto que aún era nuestro bien hasta una época reciente -el secreto que daba profundidad a las personas y podía ser un gran tema novelesco. Pero quiero permanecer optimista respecto al porvenir de la literatura y estoy persuadido que los escritores del futuro asegurarán el relevo como lo ha hecho cada generación desde Homero...

Y por cierto, un escritor, como cualquier otro artista, a pesar de estar atado a su época de manera tan estrecha que no le escapa, y que el único aire que respira es lo que llamamos en francés " l'air du temps », expresa siempre en sus obras algo intemporal. En las escenificaciones de las obras teatrales de Racine o de Shakespeare, importa poco que los personajes estén trajeados a lo antiguo o que un director quiera vestirlos de blue jeans y de chaqueta de cuero. Son detalles sin importancia. Uno olvida, al leer Tolstoi, que Ana Karenina lleva vestidos de 1870, tan cercana nos es después de un siglo y medio. Y luego algunos escritores, 
como Edgar Poe, Melville o Stendhal, son mejor entendidos doscientos años después de su muerte que por los que eran sus contemporáneos.

En definitiva, ¿a qué distancia exacta está un novelista? El margen de la vida para describirla, porque si uno está hundido en ella -en la acción - tiene de ella una imagen confusa. Pero esta ligera distancia no impide el poder de identificación que es el suyo frente a sus personajes y las y los que los inspiraron en la vida real. Flaubert dijo: « Madame Bovary, c'est moi. » Y Tolstoi se identificó enseguida con la que había visto una noche echarse debajo de un tren, en una estación de Rusia. Y este don de identificación iba tan lejos que Tolstoi se confundía con el cielo y el paisaje que describía y que absorbía todo, hasta el más ligero parpadeo de pestaña de Ana Karenina. Este estado segundo es lo contrario del narcisismo pues supone a la vez un olvido de sí mismo y una concentración muy fuerte, para ser receptivo al menor detalle. Esto supone también una cierta soledad. Ella no es un ensimismamiento, sino que permite alcanzar un grado de atención y de hiperlucidez frente al mundo exterior para transponerlo a una novela.

Siempre he creído que el poeta y el novelista daban misterio a los seres que parecen sumergidos por la vida cotidiana, a las cosas en apariencia banales, -y esto a fuerza de observarlos con una atención sostenida y de manera casi hipnótica. Bajo su mirada, la vida corriente acaba rodeándose de misterio y tomando una especie de fosforescencia que no tenía a primera vista pero que estaba oculta en profundidad. Es el papel del poeta y del novelista, y del pintor también, de desvelar este misterio y esta fosforescencia que se encuentran en el fondo de cada persona. Pienso en mi lejano primo, el pintor Amedeo Modigliani, cuyos cuadros más estremecedores son aquellos en que escogió como modelos unos anónimos, niños y chicas de las calles, sirvientas, pequeños campesinos, jóvenes aprendices. Los pintó de un trazo agudo que recuerda la gran tradición toscana, la de Botticelli y de los pintores sieneses del Quattrocento. Así les dio - o mejor desveló- toda la gracia y la nobleza que estaban en ellos bajo su humilde apariencia. El trabajo del novelista debe ir en ese sentido. Su imaginación, lejos de deformar la realidad, debe penetrarla en profundidad y revelar esta realidad a sí misma, con la fuerza de los infrarrojos y de los ultravioletas para detectar lo que se 
esconde detrás de las apariencias. Y no estaría lejos de creer que en el mejor de los casos, el novelista es una especie de vidente e incluso de visionario. Y también un sismógrafo, dispuesto a grabar los movimientos más imperceptibles.

Siempre he dudado antes de leer la biografía de tal o tal escritor que admiraba. Los biógrafos se detienen a veces en pequeños detalles, en testimonios no siempre exactos, en rasgos de carácter que parecen desconcertantes o decepcionantes, y todo eso me evoca esos chisporroteos que interfieren algunas emisiones de radio y vuelven inaudibles las músicas o las voces. Solo la lectura de sus libros nos hace entrar en la intimidad de un escritor y es ahí que está en lo mejor de sí mismo y que nos habla en voz baja sin que su voz esté interferida por el menor parásito.

Pero al leer la biografía de un escritor, uno descubre a veces un acontecimiento memorable de su niñez que fue como una matriz de su obra futura y sin que siempre haya tenido de ello una clara conciencia; este acontecimiento memorable ha vuelto, bajo diversas formas, a habitar sus libros. Hoy, pienso en Alfred Hitchcock, que no era un escritor pero cuyas películas tienen sin embargo la fuerza y la cohesión de una obra novelesca. Cuando su hijo tenía cinco años, el padre de Hitchcock le había encargado llevar una carta a un amigo suyo, comisario de policía. El niño le había entregado la carta y el comisario lo había encerrado en esa parte enrejada de la comisaría que sirve de celda y donde guardan durante la noche a los delincuentes más diversos. El niño, aterrorizado, había esperado durante una hora, antes de que el comisario lo libere y le diga: «Si te conduces mal en la vida, sabes ahora lo que te espera.» Ese comisario de policía, que tenía verdaderamente raros principios de educación, está probablemente en el origen del clima de suspenso y de inquietud que encontramos en todas las películas de Alfred Hitchcock.

No quisiera fastidiarlos con mi caso personal pero creo que algunos episodios de mi infancia sirvieron de matriz a mis libros, más tarde. Me encontraba muy a menudo lejos de mis padres, en casa de amigos, a quienes me confiaban y de quienes no sabía nada, y en lugares y casas que se sucedían. En el momento, un niño no se asombra de nada, y aun si se encuentra en situaciones insólitas, le parece perfectamente natural. Es mucho más tarde que mi infancia me pareció enigmática y que traté 
de saber más de esas diferentes personas, a quienes mis padres me habían confiado y esos diferentes lugares que cambiaban sin parar. Pero no logré identificar a la mayoría de esas gentes ni ubicar con una precisión topográfica todos esos lugares y esas casas del pasado. Esta voluntad de resolver enigmas sin lograrlo de verdad y de tratar de penetrar un misterio me dio deseos de escribir, como si la escritura y lo imaginario pudieran ayudarme a resolver por fin esos enigmas y esos misterios.

Y como se trata de «misterios», pienso, por una asociación de ideas, en el título de una novela francesa del siglo XIX: Los misterios de París. La gran ciudad, en este caso París, mi ciudad natal, está relacionada con mis primeras impresiones de infancia y esas impresiones eran tan fuertes que, desde entonces, nunca dejé de explorar los «misterios de París». Me ocurría, a los nueve o diez años, pasear solo, y a pesar del temor de perderme, ir cada vez más lejos, en barrios que no conocía, en la orilla derecha del Sena. Era en pleno día y eso me tranquilizaba. Al principio de la adolescencia, me esforzaba en vencer mi miedo y en aventurarme por la noche, hacia barrios aún más lejanos, por el metro. Es así que uno hace el aprendizaje de la ciudad y, en eso, seguí el ejemplo de la mayoría de los novelistas que admiraba y para quienes, desde el siglo XIX, la gran ciudad -que se llama París, Londres, San Petersburgo, Estocolmo- fue el decorado y uno de los temas principales de sus libros.

Edgar Poe en su cuento «El hombre de las multitudes» fue uno de los primeros en evocar todas esas olas humanas que observa detrás de los cristales de un café y que se suceden interminablemente en las aceras. Localiza un hombre viejo de aspecto extraño y lo sigue durante la noche en diferentes barrios de Londres para saber más de él. Pero el desconocido es «el hombre de las multitudes» y es vano seguirlo, porque siempre quedará anónimo, y no nos enteraremos de nada sobre él. No tiene existencia individual, sencillamente es parte de esa masa de transeúntes que caminan en filas cerradas o se empujan y pierden en las calles.

Y pienso también en un episodio de la juventud del poeta Thomas De Quincey, que lo marcó para siempre. En Londres, en la multitud de Oxford Street, se había unido con una joven, uno de esos encuentros de 
casualidad que uno hace en una gran ciudad. Había pasado varios días en su compañía y había debido dejar Londres por algún tiempo. Habían convenido que al cabo de una semana, ella lo esperaría cada tarde a la misma hora en la esquina de Tichfield Street. Pero nunca volvieron a encontrarse. «Seguramente estuvimos muchas veces en búsqueda uno de otro, en el mismo momento, a través del enorme laberinto de Londres; quizás estuvimos separados solo por unos pocos metros -no se necesita más para llegar a una separación eterna.»

Para quienes nacieron y vivieron en ellos, a medida que los años pasan, cada barrio, cada calle de una ciudad, evoca un recuerdo, un encuentro, una pena, un momento de felicidad. Y a menudo la misma calle está relacionada para uno con recuerdos sucesivos, de manera que gracias a la topografía de una ciudad, es toda su vida la que vuelve a la memoria por capas sucesivas, como si uno pudiera descifrar las escrituras superpuestas de un palimpsesto. Y también la vida de los demás, de esos miles y miles de desconocidos, cruzados en las calles o en los pasillos del metro en las horas pico.

Es así que en mi juventud, para ayudarme a escribir, trataba de encontrar viejos directorios de París, sobre todo aquellos en que los apellidos están catalogados por calles con los números de los edificios. Tenía la impresión, página tras página, de tener ante los ojos una radiografía de la ciudad, pero de una ciudad hundida, como la Atlántida, y de respirar el olor del tiempo. A causa de los años que habían transcurrido, las únicas huellas que habían dejado esos miles y miles de desconocidos, eran sus apellidos, sus direcciones y números de teléfono. A veces, un apellido desaparecía, de un año a otro. Había algo vertiginoso en hojear esos antiguos directorios y pensar que en adelante los números de teléfono no contestarían. Más tarde, debían impactarme los versos de un poema de Ossip Mandelstam:

Volví en mi ciudad familiar hasta los sollozos

Hasta los ganglios de la niñez, hasta las nervaduras debajo de la piel.

¡Petersburgo! [...]

De mis teléfonos, tienes los números.

¡Petersburgo! Tengo las direcciones de antaño

En que reconozco a los muertos por sus voces. 
Sí, me parece que es al consultar esos antiguos directorios de París que tuve deseos de escribir mis primeros libros. Era suficiente subrayar con lápiz el apellido de un desconocido, su dirección y número de teléfono e imaginar cual había sido su vida, entre esos centenares y centenares de miles de apellidos.

Uno puede perderse o desaparecer en una gran ciudad. Puede hasta cambiar de identidad y vivir una nueva vida. Podemos dedicarnos a una muy larga investigación para encontrar las huellas de alguien, teniendo solo al principio una o dos direcciones en un barrio perdido. La breve indicación que figura a veces en las fichas de búsqueda siempre encontró un eco en mí: Último domicilio conocido. Los temas de la desaparición, de la identidad, del tiempo que pasa están estrechamente relacionados con la topografía de las grandes ciudades. Por eso es que, desde el siglo XIX, han sido a menudo el dominio de los novelistas y algunos entre los más grandes de ellos están asociados a una ciudad: Balzac y París, Dickens y Londres, Dostoievski y San-Petersburgo, Tokyo y Nagai Kafû, Estocolmo y Hjalmar Söderberg.

Pertenezco a una generación que se ha visto influenciada por estos novelistas y que quiso, a su vez, explorar lo que Baudelaire llamaba «los pliegues sinuosos de las grandes capitales». Claro que desde hace cincuenta años, es decir, la época en que los adolescentes de mi edad sentían sensaciones muy fuertes al descubrir su ciudad, estas han cambiado. Algunas, en América y en lo que se llamaba el tercer mundo, se han vuelto «megalópolis» de dimensiones inquietantes. Sus habitantes están compartimentados en barrios muchas veces abandonados, y en un clima de guerra social. Los tugurios son cada vez más numerosos y cada vez más tentaculares. Hasta el siglo XX, los novelistas guardaban una visión de alguna manera « romanticista » de la ciudad, no tan diferente de la de Dickens o de Baudelaire. Y he aquí por qué me gustaría saber cómo los novelistas del porvenir evocarán esas gigantescas concentraciones urbanas en obras de ficción.

Han tenido la indulgencia de aludir, en cuanto a mis libros, al «arte de la memoria con que están evocados los destinos humanos más inaprensibles.» Pero este halago sobrepasa mi persona. Esta memoria particular que trata de recolectar algunos fragmentos del pasado y las 
pocas huellas que dejaron en esta tierra anónimos y desconocidos está también relacionada con mi fecha de nacimiento: 1945. Haber nacido en 1945, después de que ciudades fueron destruidas y que poblaciones enteras hubieron desaparecido, probablemente me ha vuelto, como a los de mi edad, más sensible a los temas de la memoria y del olvido.

Me parece, desgraciadamente, que la búsqueda del tiempo perdido ya no puede hacerse con la fuerza y la franqueza de Marcel Proust. La sociedad que describía aún era estable, una sociedad del siglo XIX. La memoria de Proust hace resurgir el pasado en sus menores detalles, como un cuadro vivo. Tengo la impresión que hoy en día la memoria es mucho menos segura de sí misma y que debe luchar sin cesar contra la amnesia y contra el olvido. A causa de esa capa, de esa masa de olvido que recubre todo, no logramos captar sino fragmentos del pasado, huellas interrumpidas, destinos humanos huidizos y casi inaprensibles.

Pero es probablemente la vocación del novelista, delante de esta gran página blanca del olvido, hacer resurgir algunas palabras medio borradas, como esos icebergs perdidos que derivan en la superficie del océano. 